\title{
PENGARUH PEMBERIAN ECCENTRIC STRENGTHENING EXERCISES TERHADAP PERUBAHAN FOOT ALIGNMENT, MALLEOLUS HEIGHT DAN TINGKAT AGILITY PADA PEMAIN BULU TANGKIS JUNIOR DI KOTA MAKASSAR
}

\author{
Hermilasari, Adi Ahmad Gondo, Irianto \\ Program Studi Fisioterapi, Fakultas Keperawatan, Universitas Hasanuddin, Makassar - Sulawesi Selatan, Indonesia
}

Corresponding author:

\section{Hermilasari}

Program Studi Fisioterapi, Fakultas Keperawatan, Universitas Hasanuddin, Makassar - Sulawesi Selatan, Indonesia Email: Sari.hermila858@gmail.com

\section{Article Info:}

Received: 15 May 2019

Revised: 10 June 2019

Accepted: 10 June 2019

Available online: 21 Oct 2019

Keywords: Foot Alignment,

Malleolus Height, Agility,

Eccentric Strengthening Exercise, Badminton

DOI: $10.20956 / n m s j . v 4 i 2.6524$

\begin{abstract}
Introduction: Foot alignment is the alignment of the body's vertical axis to the normal position of the foot which affects mechanical alignment and dynamic functions of the inferior limb, so as to provide support and maintain body balance. Malalignment in the foot structure shows biomechanical disturbances, such as overpronation allowing changes in body structure and function which can affect the inferior extremities and superior extremities.

Methods: This study aims to determine the effect of the Eccentric Strengthening Exercises on changes in Foot Alignment, Malleolus Height and Agility Level. This research is a quasi-experimental design study with a time-series experimental design. The study population was junior badminton players in Makassar City aged 11-15 years old. Study sampling using purposive sampling technique with a sample size of 32 people. Data collection was done through primary data retrieval through the measurement instrument of foot alignment, malleolus height and agility. Analysis of collected data were using the Shapiro Wilk Test. Analysis of difference of the pre-test and post-test groups were using Repeated anova test for normal distributed data and Friedman test for abnormally distributed data.

Results: From the measurement results, a significant value of $p=0.0001$ ( $p$ $<0.05$ ) was obtained after 18 times of exercise.

Conclusion: This research shows that there is an influence of eccentric strengthening exercise on changes in foot alignment, malleolus height and agility level in junior badminton players in Makassar.
\end{abstract}

\section{PENDAHULUAN}

Bulu tangkis telah menjadi salah satu olahraga yang sangat digemari oleh seluruh lapisan masyarakat. Untuk dapat berprestasi, pemain bulutangkis harus menguasai skill dan teknikteknik dasar seperti, cara memegang raket (grips), sikap siap (stance atau ready position), gerakan kaki (footwork), dan gerak memukul (stroke). ${ }^{1}$ Salah satu skill yang paling mendasar dalam permainan bulu tangkis adalah footwork (gerakan langkah kaki). Gerakan yang paling sering dilakukan dalam footwork adalah lunge dimana gerakan tersebut dilakukan sebanyak $15 \%$ dalam permainan bulu tangkis. Pola lunges tersebut dapat mempengaruhi kinematika ekstremitas inferior. ${ }^{2}$ Dalam melakukan footwork, dibutuhkan agility yang tinggi, koordinasi gerak sendi, kontraksi otot yang baik serta penguasaan teknik. 
Oleh karena itu, penguasaan seluruh aspek tersebut manjadi poin penting yang harus dimiliki pemain bulutangkis untuk mendukung keterampilan pada saat bermain agar terhindar dari cedera olahraga. ${ }^{3}$

Dari beberapa penelitian, diperoleh bahwa cedera yang paling sering terjadi pada pemain bulu tangkis adalah cedera pada ekstremitas inferior. Sebanyak $60 \%$ terjadi pada knee, ankle, gastrocnemius muscle dan soleus muscle. Pemain yang paling beresiko mengalami cedera adalah pemain bulu tangkis di bawah usia 20 tahun. Perubahan biomekanik yang terjadi akibat berubahnya foot alignment ke arah overpronation, dapat membebani otot-otot di daerah lutut dan kaki untuk bekerja lebih keras dalam mempertahankan posisi tubuhnya agar dapat berdiri stabil. Overpronation merupakan kondisi yang menggambarkan kaki berada dalam posisi pronasi, tetapi dianggap berlebihan dari kaki normal pada umumnya. ${ }^{4}$ Overpronation dapat diukur dengan pengukuran rearfoot angle dan malleolus height. ${ }^{5}$ Pemanfaatan metode latihan yang umum dilakukan untuk memberikan efek positif dalam meningkatkan kualitas fungsional dari sistem tubuh adalah eccentric strengthening exercise. Latihan tersebut bertujuan memperpanjang otot saat berkontraksi disertai dengan penguatan dan pemanjangan otot untuk menciptakan perubahan viskoelastik pada otot, serta menyebabkan hipertrofi otot, mengaktifkan muscle fyber tipe II (fast twich), peningkatan jumlah sarcomer dan fasicle lengh serta mengoptimalkan neuralmuscular control dimana semuanya berkontribusi pada peningkatan fungsi otot. ${ }^{6,7}$

\section{METODE}

\section{Lokasi dan Rancangan Penelitian}

Penelitian ini dilaksanakan di Gedung Olah Raga (GOR) Mutiara, GOR Soulmate, dan GOR Anugrah Makassar yang merupakan lokasi latihan PB Avanti dan PB Filawatch. Jenis penelitian ini merupakan penelitian quasi experimental design dengan jenis rancangan time series experimental.

\section{Populasi dan Sampel}

Populasi dalam penelitian ini adalah atlet bulu tangkis junior berusia 11-15 tahun yang sedang aktif mengikuti latihan di PB Avanti dan PB Filawatch, Kota Makassar. Berdasarkan kriteria inklusi, diperoleh sampel penelitian sebanyak 32 orang. Dengan kriteria inklusi adalah atlet bulu tangkis junior di Kota Makassar, berjenis kelamin laki-laki, memiliki nilai Index Massa Tubuh (IMT) normal, hadir untuk mengikuti pengukuran, bersedia menjadi responden, dan tidak diberikan exercise fisioterapi lainnya. Sedangkan kriteria eksklusi dalam penelitian ini, yaitu tidak memiliki riwayat penyakit cardiovaskuler, riwayat cedera dan post operasi ekstremitas

\section{Metode Pengumpulan Data}

Pengumpulan data dilakukan dengan melakukan observasi terlebih dahulu. Informasi mengenai karakteristik dan keadaan umum responden, meliputi nama, umur, riwayat penyakit, dan riwayat cedera diketahui dengan melakukan wawancara langsung. Nilai IMT responden diambil dengan mengukur berat badan menggunakan timbangan dan tinggi badan menggunakan mikrotoise. Selanjutnya, pengambilan data awal (pre test) dilakukan melalui pengukuran rearfoot angle, malleolus height, dan agility. Pemberian eccentric strenghtening exercise dilakukan tiga kali seminggu selama enam minggu dengan post test sebanyak enam kali dan dicatat setiap minggunya.

\section{Analisis Data}

Data hasil pengukuran rearfoot angle, malleolus height, dan agility diolah menggunakan software SPSS 22 dengan menggunakan Uji Friedman untuk distribusi data tidak normal dan Repeated Measure ANOVA untuk distribusi data normal untuk melihat pengaruh pre dan post eccentric strengthening exercise dan dilakukan post hoc analysis untuk melihat peningkatan tiap minggunya. Uji pearson juga dilakukan untuk menganalisis hubungan antara rearfoot angle, malleolus height, dengan agility. Hasil analisis data disajikan dalam bentuk tabel, grafik, dan narasi.

\section{HASIL}

Hasil penelitian menunjukkan dari 30 sampel, pemain bulu tangkis junior laki-laki di PB Avanti dan Filawatch paling banyak berusia 11 dan 13 tahun. Hasil pengukuran nilai rearfoot angle dan malleolus height mengalami peningkatan setelah enam minggu. Hasil Uji Friedman menunjukan adanya pengaruh eccentric strenghtening exercise terhadap perubahan rearfoot angle $(\mathrm{p}=0,0001)$ setelah 18 kali pemberian latihan, dan perubahan 
sudah dapat dilihat setelah pemberian 6 kali latihan. Hasil Uji Friedman juga menunjukkan adanya pengaruh eccentric strenghtening exercise terhadap perubahan malleolus height kanan lateral, malleolus height kiri medial, malleolus height kiri lateral $(\mathrm{p}=0,0001)$ dan hasil Repeated ANOVA pada malleolus height kanan medial menunjukkan ada pengaruh eccentric strenghtening exercise setelah 18 kali pemberian latihan, perubahan dapat dilihat setelah 6 kali pemberian latihan. Sementara itu, Nilai rata-rata agility test berbeda dengan pengukuran rearfoot angle dan malleolus height. Hasil rata-rata agility mengalami penurunan setiap minggunya, tetapi penurunan ini bersifat positif sebab atlet semakin cepat menyelesaikan agility test tersebut.

Berdasarkan uji Repeated ANOVA, hasil agility test menunjukkan nilai probabilitas sebesar $0,0001(\mathrm{p}<0,05)$ yang berarti terdapat pengaruh eccentric strenghtening exercise terhadap agility. Uji Pearson juga dilakukan untuk melihat hubungan antara rearfoot angle, malleolus height dengan agility. Hasilnya menunjukkan bahwa tidak ada hubungan antara rearfoot angle kanan, rearfoot angle kiri, malleolus height kanan lateral, malleolus height kiri lateral dengan agility, berbeda dengan malleolus height kanan medial dan malleolus height kiri medial yang menunjukkan adanya hubungan dengan agility, dengan nilai $\mathrm{p}=0,037(\mathrm{p}<0,05)$ yang berarti ada hubungan antara pengukuran malleolus height kanan medial dengan agility, dan nilai $\mathrm{p}=0,023$ $(\mathrm{p}<0,05)$ yang berarti ada hubungan antara pengukuran malleolus height kiri medial dengan agility

Tabel 1 Karakteristik Sampel Penelitian

\begin{tabular}{ccc}
\hline $\begin{array}{c}\text { Karakteristik } \\
\text { Sampel }\end{array}$ & Frequency & $\begin{array}{c}\text { Persentase } \\
(\%)\end{array}$ \\
\hline Usia & & \\
11 & 9 & 30,0 \\
12 & 2 & 6,7 \\
13 & 9 & 30,0 \\
14 & 7 & 23,3 \\
15 & 3 & 10,0 \\
\hline Total & 30 & 100 \\
\hline
\end{tabular}

Tabel 3 Hasil Analisis Data Pengukuran Rearfoot Angle dan Malleoulus Height Dengan Tingkat Agility

\begin{tabular}{|c|c|c|c|c|}
\hline \multirow{2}{*}{\multicolumn{2}{|c|}{$\begin{array}{c}\text { Kelompok } \\
\text { Post test } 6 \\
\text { Rearfoot } \\
\text { angle kanan }\end{array}$}} & $\mathrm{p}$ & $\mathrm{R}$ & $r^{2}$ \\
\hline & & 0,914 & $-0,021$ & 0,0004 \\
\hline \multirow{5}{*}{ Agility } & $\begin{array}{c}\text { Post test } 6 \\
\text { Rearfoot } \\
\text { angle kiri }\end{array}$ & 0,311 & $-0,192$ & 0,036 \\
\hline & $\begin{array}{l}\text { Post test } 6 \\
\text { malleolus } \\
\text { height } \\
\text { kanan } \\
\text { lateral }\end{array}$ & 0,131 & $-0,282$ & 0,079 \\
\hline & $\begin{array}{c}\text { Post test } 6 \\
\text { malleolus } \\
\text { height kiri } \\
\text { lateral }\end{array}$ & 0,074 & $-0,331$ & 0,109 \\
\hline & $\begin{array}{l}\text { Post test } 6 \\
\text { malleolus } \\
\text { height } \\
\text { kanan } \\
\text { medial }\end{array}$ & 0,037 & $-0,383$ & 0,146 \\
\hline & $\begin{array}{c}\text { Post } 6 \text { test } \\
\text { malleolus } \\
\text { height } \text { kiri } \\
\text { medial }\end{array}$ & 0,023 & $-0,413$ & 0,170 \\
\hline
\end{tabular}

Keterangan: $\mathrm{p}=$ probabilitas hasil uji correlate Sumber: Data Primer, 2019 


\section{Tabel 2 Hasil Analisis Data}

\begin{tabular}{|c|c|c|c|c|c|c|c|c|c|c|c|c|c|c|}
\hline \multirow{3}{*}{ Kelompok } & \multicolumn{14}{|c|}{ Pengukuran $(\mathrm{n}=\mathbf{3 0})$} \\
\hline & \multicolumn{2}{|c|}{$\begin{array}{l}\text { Rearfoot Angle } \\
\text { Kanan }\end{array}$} & \multicolumn{2}{|c|}{ Rearfoot Angle Kiri } & \multicolumn{2}{|c|}{$\begin{array}{c}\text { Malleolus Height Kanan } \\
\text { Lateral }\end{array}$} & \multicolumn{2}{|c|}{$\begin{array}{c}\text { Malleolus Height } \\
\text { Kiri Lateral } \\
\end{array}$} & \multicolumn{2}{|c|}{$\begin{array}{c}\text { Malleolus Height } \\
\text { Kanan Medial }\end{array}$} & \multicolumn{2}{|c|}{$\begin{array}{c}\text { Malleolus Height Kiri } \\
\text { Medial }\end{array}$} & \multicolumn{2}{|c|}{ Agility } \\
\hline & $\begin{array}{c}\text { Mean } \\
\text { rank }\end{array}$ & $\mathrm{P}$ & Mean rank & $\mathrm{P}$ & Mean rank & $\mathrm{P}$ & Mean rank & $\mathrm{P}$ & Mean rank & $\mathrm{P}$ & $\begin{array}{c}\text { Mean } \\
\text { difference }\end{array}$ & $\mathrm{P}$ & $\begin{array}{c}\text { Mean } \\
\text { difference } \\
\end{array}$ & $\mathrm{P}$ \\
\hline \multicolumn{15}{|l|}{3 kali latihan } \\
\hline Pre test & 2,07 & 1,000 & 2,17 & 1,000 & 2,02 & 1,000 & 2,27 & 1,000 & 2,53 & 1,000 & 0,0001 & & 2,288 & 0,0001 \\
\hline Post test 1 & 2,07 & & 2,17 & & 2,02 & & 2,27 & & 2,53 & & & & & \\
\hline \multicolumn{15}{|l|}{6 kali latihan } \\
\hline Post test 1 & 2,07 & 0,014 & 2,17 & 0,020 & 2,02 & 0,001 & 2,27 & 0,016 & 2,53 & 0,034 & $-0,017$ & 0,057 & 0,387 & 0,158 \\
\hline Post test 2 & 2,58 & & 2,55 & & 3,03 & & 2,83 & & 2,88 & & & & & \\
\hline \multicolumn{15}{|l|}{9 kali latihan } \\
\hline Post test 2 & 2,58 & 0,0001 & 2,55 & 0,0001 & 3,03 & 0,003 & 2,83 & 0,003 & 2,88 & 0,016 & $-0,037$ & 0,094 & 0,779 & 0,001 \\
\hline Post test 3 & 3,93 & & 3,90 & & 4,07 & & 3,70 & & 3,50 & & & & & \\
\hline \multicolumn{15}{|l|}{12 kali latihan } \\
\hline Post test 3 & 3,93 & 0,001 & 3,90 & 0,001 & 4,07 & 0,005 & 3,70 & 0,000 & 3,50 & 0,003 & $-0,093$ & 0,0001 & 0,424 & 0,0001 \\
\hline Post test 4 & 4,73 & & 4,77 & & 4,75 & & 5,02 & & 4,53 & & & & & \\
\hline \multicolumn{15}{|l|}{15 kali latihan } \\
\hline Post test 4 & 4,73 & 0,0001 & 4,77 & 0,0001 & 4,75 & 0,001 & 5,02 & 0,000 & 4,53 & 0,001 & $-0,053$ & 0,002 & 0,346 & 0,016 \\
\hline Post test 5 & 5,82 & & 5,68 & & 5,75 & & 5,60 & & 5,52 & & & & & \\
\hline \multicolumn{15}{|l|}{18 kali latihan } \\
\hline Post test 5 & 5,82 & 0,0001 & 5,68 & 0,0001 & 5,75 & 0,003 & 5,60 & 0,002 & 5,52 & 0,0001 & $-0,077$ & 0,0001 & 0,636 & 0,0001 \\
\hline \multirow[t]{2}{*}{ Post test 6} & 6,80 & & 6,77 & & 6,37 & & 6,32 & & 6,50 & & & & & \\
\hline & Friedman & 0,0001 & Friedman & 0,0001 & Friedman & 0,0001 & Friedman & 0,0001 & Friedman & 0,0001 & $\begin{array}{l}\text { Repetead } \\
\text { Anova }\end{array}$ & 0,0001 & $\begin{array}{l}\text { Repetead } \\
\text { Anova }\end{array}$ & 0,0001 \\
\hline
\end{tabular}




\section{PEMBAHASAN}

Eccentric strenghtening exercise merupakan suatu model latihan yang dilakukan dengan memperpanjang otot saat berkontraksi dimana otot tersebut dikuatkan disertai dengan pemanjangan otot untuk menciptakan perubahan viskoelastis pada otot. Berubahnya foot alignment ke arah overpronation akan membebani otot-otot di daerah lutut dan kaki untuk bekerja lebih keras dalam mempertahankan posisi tubuhnya. Tekanan konstan yang dialami otot karena postur abnormal yang berkepanjangan serta gerakan berulang akan memberikan adaptasi neurologis dan merubah biomekanik sehingga menyebabkan muscle imbalance. ${ }^{8}$

Pemberian eccentric strengthening yang terdiri dari sliding leg curl, heel drop dan spread out masing-masing digunakan untuk melatih dan membangun struktur jaringan otot di ekstremitas inferior, yaitu otot hamstring, gastrocnemius, dan otot-otot intrinsic yang merupakan superficial back line yang saling berintegrasi satu sama lain.912

Ada beberapa faktor yang mempengaruhi perubahan hasil pengukuran rearfoot angle dan malleolus height sejalan dengan diberikan exercise tersebut yakni posisi dan cara melakukan latihan sehingga dapat memaksilkan hasil dari efek yang ditimbulkan oleh latihan tersebut, dimana penguatan yang eccentric strenghtening exercise memberikan pengaruh yang positif dapat mempercepat atau mengoptimalkan peningkatan kekuatan otot selama kontraksi eccentric terjadi pada otot yakni otot-otot yang berada pada superfisial back line seperti otot intrinsic pada pedis, gastrocnemius dan hamstring tidak hanya hipertrofi otot dan adaptasi, tetapi juga merangsang mineralisasi tulang dan remodeling tendon dan mengoptimalkan kinerja dan peningkatan daya tahan, serta saat pemberian latihan eccentric strenghtening exercise yakni sliding leg curl, heel drop dan spread out terjadi transmisi kekuatan otot pada otot-otot yang berada pada superficial back line sepanjang rantai myofascial seperti otot intrinsik, gastrocnemius dan hamstring dapat memberikan peningkatan kekuatan pada otot dan peningkatan longitudinal medial arcus melalui exercise sehingga dapat mengubah overpronation menjadi posisi netral pada pedis sehingga tinggi malleolus medial dan lateral akan meningkat seiring dengan peningkatan longitudinal medial arcus. ${ }^{13,14}$
Studi neurofisiologis menunjukkan ada dua tahapan latihan eccentric strenghtening exercise yang terpisah. Di tahap pertama yakni 2-3 minggu setelah pemberian latihan eccentric srenghtening exercise mempengaruhi rangsangan motorneuron yang mempengaruhi cara aktivasi serat otot. Pada tahap kedua dimulai 4-5 minggu setelah pemberian latihan, morfologi, histokimia, dan biokimia secara bertahap telah mengalami perubahan yang secara signifikan dapat mempengaruhi serat otot dalam menghasilkan kekuatan. $^{15}$ Oleh karena dari hasil penelitian didapatkan bahwa ada beberapa responden yang telah mengalami peningkatan pada minggu kedua setelah pemberian 6 kali latihan eccentric strenghtening exercise, dan untuk melihat peningkatan progresif dalam massa otot terjadi pada minggu ke 3-4 sebagai tahap adaptasi setelah pemberian latihan eccentric strenghtening exercise.

Pemberian eccentric strengthening exercise dengan daya yang tinggi, menghasilkan peningkatan spesifik muscle fiber tipe II (fast twitch) pasca 24 jam exercise dan bertanggung jawab untuk memberikan atlet kecepatan, kelincahan, kecepatan dan kekuatan pada otot ekstremitas bawah sehingga dapat meningkatkan agility. ${ }^{16}$

Hasil penelitian tersebut menunjukkan adanya perubahan setelah pemberian 3 kali eccentric strengthening exercise dilihat dari waktu yang dibutuhkan responden untuk menyelesaikan badcamp test agility yang semakin berkurang, namun minggu kedua setelah pemberian 6 kali latihan terjadi peningkatan waktu yang dibutuhkan lebih lama untuk menyelasaikan test agility salah satu faktornya adalah kelelahan dimana hilangnya kapasitas untuk mengembangkan kekuatan dan kecepatan otot, yang dihasilkan dari aktivitas otot, ${ }^{17}$ dan untuk minggu ketiga sampai minggu ke enam tingkat agility responden meningkat kembali dengan melihat kurangnya waktu yang dubutuhkan untuk menyelesaikan test.

Struktural pada malleolus medial kanan dan malleolus medial kiri terdapat hubungan dengan peningkatan agility, diman peningkatan tulang navicular memiliki peran penting terhadap lengkungan tinggi arcus, hal ini dapat mempengaruhi tinggi dari malleolus medial 
dikarenakan malleolus medial saling terhubung dengan beberapa tulang di ankle terutama tulang navicular, ketika terjadi peningkatan tinggi arcus maka posisi kaki overpronasi akan perlahan menuju kearah yang normal disertai dengan peningkatan tinggi malleoulus medial yang awalnya lebih rendah. Hal ini juga sejalan dengan teori dalam buku anatomy trains yang mengatakan bahwa didalam tubuh terdapat fascia sebagai garis continuitas yang saling menghubungkan satu sama lain, dimana integritas malleolus diyakini sebagai penentu utama stabilitas pergelangan kaki dimana struktur tinggi dari malleolus akan menjaga dan mempermudah kaki dalam melakukan gerakan-gerakan yang sulit, agar tidak mudah cedera, dan mampu mengimbangi lawan misalnya pada saat melakukan footwork dalam permainan bulutangkis, sehingga dapat mendukung agility untuk mengubah posisi tubuh untuk melakukan gerakan dengan cepat dan tepat tanpa kehilangan keseimbangan pada saat bergerak secara berturut-turut dalam durasi cepat dan singkat diikuti dengan penguatan otot-otot intrinsic, gastrocnemius dan hamstring yang dapat mengurangi tingkat cidera pada saat berolahraga namun agility tidak hanya dipengaruhi oleh struktural ekstremitas inferior, tetapi Kemampuan kognitif dan pengambilan keputusan oleh atlet juga berkontribusi dalam aqility. ${ }^{18}$

\section{KESIMPULAN}

Kesimpulan dari penelitian ini, yaitu terdapat perbedaan rearfoot angle, malleolus height dan tingkat agility pemain bulu tangkis junior setelah pemberian eccentric strenghtening exercise dengan nilai $p=0,0001(p>0,05)$ yang berarti ada perubahan bermakna setelah 18 kali latihan. Selain itu, terdapat juga hubungan antara malleolus height kanan medial, malleolus height kiri medial dengan agility, tetapi tidak terdapat hubungan antara rearfoot angle kanan, rearfoot angle kiri, malleolus height kanan lateral dan malleolus kiri lateral dengan agility pada atlet bulu tangkis junior di Kota Makassar. Hasil penelitian ini diharapkan agar supaya pemain bulu tangkis junior dapat mengaplikasikan eccentric strenghtening exercise untuk mendukung performa saat bermain. Untuk penelitian lebih lanjut diharapkan dapat mengontrol variabelvariabel perancuh serta menggunakan alat ukur yang lebih canggih dan akurat

\section{DAFTAR PUSTAKA}

1. Mangun, F. A., \& Budiningsih. Model Latihan Smash pada Cabang Olahraga Bulutangkis untuk Atlet Ganda. Ilmu Keolahragaan, M, 2017; 08(02), 78-91.

2. Hu, X., Li, J. X., Hong, Y., \& Wang, L. Characteristics of Plantar Loads in Maximum Forward Lunge Tasks in Badminton. (J. L. McCrory, Ed.) Plos One, 2015; 1-10.

3. Wijaya, A. Analisis Gerak Keterampilan Servis dalam Permainan Bulutangkis (Suatu Tinjauan Anatomi, Fisiologi, dan Biomekanika). Indonesia Performance Journal, 2017; 106-111.

4. Griffiths, I. Overpronation : Accurate or Parachronistic Terminology. SportEX Dynamics, 2012; 10-13.

5. Hamill, J., Knutzen, K. M., \& Derrick, T. R. Biomechanical Basis of Human Movement. Cina: Wolters Kluwer; 2015.

6. Yu, J., Park, D., \& Lee, G. Effect of Eccentric Strengthening on Pain,MuscleStrength,Endurance, and Functional Fitness Factors in Male Patients with Achilles Tendinopathy. American Journal of Physical Medicine \& Rehabilitation, 2013; 92(1), 68-76.

7. Hedayatpour, N., \& Falla, D. Physiological and Neural Adaptations to Eccentric Exercise: Mechanisms and Considerations for Training. BioMed Research International, 2015; 1-7.

8. Yu, J., Park, D., \& Lee, G. Effect of Eccentric Strengthening on Pain,MuscleStrength,Endurance, and Functional Fitness Factors in Male Patients with Achilles Tendinopathy. American Journal of Physical Medicine \& Rehabilitation, 2013; 92(1), 68-76.

9. Gal, D.-B., \& Lee, S.-Y. Comparison of The Thickness of the Gastrocnemius Through Ultrasonography During HeelDrop Exercise Performance. Physical Therapy Rehabilitation Science, 2016; 5(2), 89-94.

10. Heo, H.-J., Koo, Y.-M., \& Yoo, W.-G. Comparisonof Selective Activation of The Abductor Hallucis During Various Exercises. J Phys Ther Sci, 2011; 23(6), 915-918. 
11. Carpenter, K., Paul, S., Komet, I., \& Edeer, A. O. Volitional Hamstring Force Production During Closed Kinetic Chain Lower Extremity Exercise In Supine Position: A Randomized Controlled Trial. MOJ Yoga \& Physical Therapy, 2017; 2(4), 110-113.

12. Myers, T. W. Anatomy Trains. Edinburgh, London, New York, Oxford, Philadelphia, St Louis, Sidney, Toronro: Elsevier; 2014.

13. Vogt, M., \& Hoppeler, H. H. Eccentric Exercise: Mechanisms and Effects When Used As Training Regime or Training Adjunct. Journal of Applied Physiology, 2014; 1446-1454.

14. Myers, T. W. Anatomy Trains. Edinburgh, London, New York, Oxford, Philadelphia, St Louis, Sidney, Toronro: Elsevier; 2014.
15. W , M., \& D, L. Physiological adaptations of motor units to endurance and strength training, 2014; 21(3), 129-134.

16. Cermak, N. M., Snijder, T., McKay, B. R., Parise, G., Verdijk, L. B., Tarnopolsky, M. A., Loon, L. J. Eccentric Exercise Increases Satellite Cell Content in Type II Muscle Fibers. Medicine \& Science in Sports \& Exercise, 2012; 230-237.

17. Moreno, A. B.Speed and Agility Development and Theory, 2014; 21(1).

18. Mardhika , R. Pengaruh Latihan Resistance dan Pyometric Terhadap Kekuatan Otot Tungkai dan Kelincahan Pada Pemain Futsal. WAHANA, 2017; 68(1), 5-12 